\title{
O PROCESSO DE EROSÃO EM AMBIENTE DE SUPERFICIE SERTANEJA - VARJOTA (CE)
}

\author{
José Falcão Sobrinho* \& \\ Jurandyr Luciano Sanches Ross**
}

\section{RESUMO:}

O presente ensaio objetiva analisar a erosão do solo em ambiente de superfície sertaneja do semi-árido cearense. O município de Varjota foi o objeto de estudo, onde foram instaladas três áreas experimentais sob diferentes usos de manejo do solo.

\section{PALAVRAS-CHAVE:}

erosão, semi-árido, superfície sertaneja, solos, agricultura.

\section{ABSTRACT:}

The present objective assay to analyze the erosion of the ground in surface environment sertaneja of the half-barren person from the state of Ceará. The city of Varjota was the study object, where three experimental areas under different uses of handling of the ground had been installed.

\section{KEY WORDS:}

erosion, half-barren, surface sertaneja, ground, agriculture.

\section{Introdução}

No presente ensaio, objetiva-se contribuir com uma amostragem, de dados de erosão do solo, analisando os componentes físicos e nutrientes químicos, com fins quantitativos, de uma área que passou por um sistema de plantio em diversas formas de uso da terra, seja em pousio, em área sistematicamente utilizada e em área com cobertura vegetal de mata. O relevo apresenta-se como base de sustentação para o desenvolvimento de tais atividades, e será abordado na forma de sua declividade, assim como a vegetação, através da forma sucessiva que a mesma apresenta e, juntamente com a precipitação, que apesar de suas irregularidades, propicia dinâmica dos nutrientes e remodelando a paisagem. Nesse contexto, a ação do homem é determinante, pois este surge como

o último agente que modifica a superfície da terra é o homem. O homem deve ser considerado diretamente como um agente geomorfológico, já que vem alterando cada vez mais as condições de denudação e de colmatação da superfície da Terra e, muitos erros têm ocorrido na geografia física por esta não ter reconhecido suficientemente que os principais processos de modelagem da Terra não podem ser inferidos com segurança com base nos processos atualmente vigentes a partir da ocupação do homem. (SAUER

\footnotetext{
* Professor Doutor da Universidade Estadual do Vale do Acaraú/UVA. E-mail: falcao@sobral.org 
1931, p. 105).

As ações dos agricultores se manifestam nesta pesquisa, pois ora o agricultor derruba a vegetação para um plantio, ora sucede o plantio em fileiras em uma determinada área, ou ainda, deixa em repouso (pousio) por algum tempo. Com isso, o referido experimento é testemunho das afirmações acima citadas.

Os dados a seguir, certamente são passíveis de várias análises da vez que o tema erosão é pouco pesquisado no estado do Ceará. Privilegiamos, para alvo de experimentação, o ambiente de superfície sertaneja, no município de Varjota (CE) (Fiqura 1).

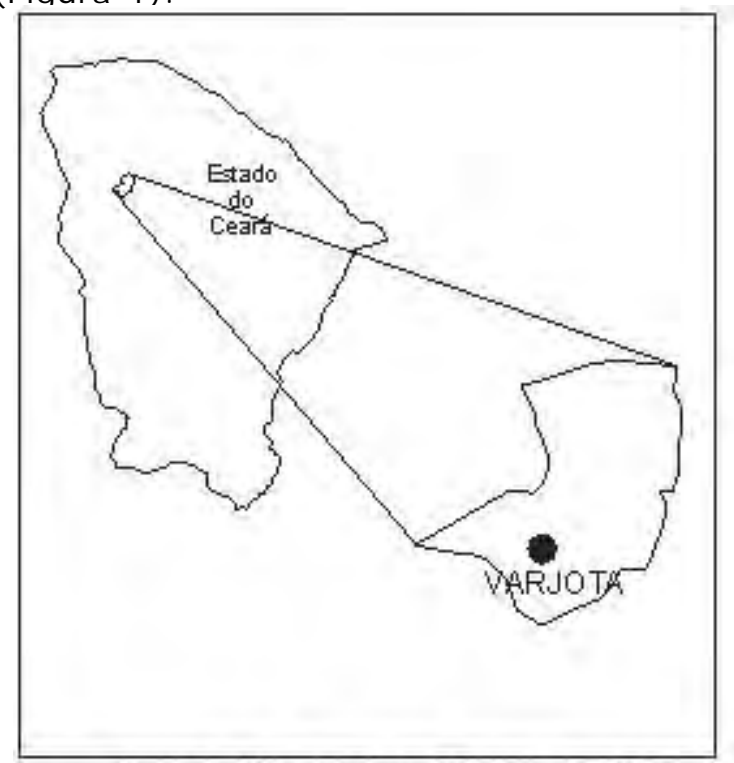

Figura 1: Município de Varjota (CE)

\section{A área de estudo}

O município de Varjota (Latitude (S) 4 응 $11^{\prime} 40^{\prime \prime}$ e Longitude (W) 40 $28^{\prime} 36^{\prime \prime}$ ), se localiza na superfície sertaneja, que é uma área deprimida localizada entre os ambientes elevados e cuja sua extensão um total de $92 \%$ da área total do estado. Em Varjota, sua dimensão ocupada toda a extensão territorial.

Com altitude inferior a $400 \mathrm{~m}$, a superfície sertaneja é área de aplainamento resultante do trabalho erosivo em que, indistintamente, diferentes litologias, colocam em destaque as rochas mais resistentes.

No aspecto geral, a morfologia das superfícies sertanejas caracteriza-se pela presença de amplas rampas de pedimento que se inclinam da base dos relevos residuais em extensão ao litoral, com isso, a altitude vai gradativamente diminuindo. Conforme Ab'Saber (1956), tendo evoluído sob condições climáticas semi-áridas, a superfície sertaneja apresenta como revestimento generalizado a caatinga, com capacidade mínima de deter ou atenuar a ação erosiva, fato este verificado em Varjota.

Neste local, uma longa extensão de área é recoberta por solos da classe dos Luvissolos Crômicos (Bruno Não Cálcicos), Neossolos Litólicos (Litólicos) e em grande extensão territorial apresenta o Argissolo (Podzólico vermelho-amarelo), este em que foi montado o experimento.

\section{Procedimentos técnicos e operacionalização das atividades}

Com base em Falcão Sobrinho e Falcão (2004), foram delimitas três áreas para objeto de estudo: a) uma área que tenha sido conservada há pelo menos 10 anos, sem intervenção antrópica; b) uma área em pousio, há pelo menos três anos e c) uma área com uso contínuo, ou seja, que esteja sendo praticado um tipo de cultura ao longo de vários anos, no caso, plantio de milho que é a cultura mais empregada no semi-árido cearense.

Foi feita uma limpeza do terreno para uniformizar a área experimental, com uso de uma enxada.

Como critério, adotamos a orientação de Falcão Sobrinho e Falcão (2004), com base nos seguintes procedimentos: O experimento foi realizado em uma área de fácil acesso, um sítio, 
evitando influência externa e, principalmente, a circulação de animais; as vertentes apresentavam declividades com semelhanças; as áreas foram representativas às condições de uso comumente encontradas na região, ou seja, prática de queimada no desbravamento e plantio sem cobertura do solo, no caso o milho ou o feijão, acrescentou-se uma área em pousio e uma outra área que estivesse com uma cobertura vegetal a pelos menos 5 anos.

Para quantificar as taxas erosivas montamos duas parcelas experimentais $(2 \mathrm{~m} \times$ 10m) em cada área, conforme Guerra (1996), sendo as mesmas divididas no cumprimento, ao meio, por uma outra chapa alumínio, ficando cada parcela, uma em solo sem vegetação e outra em solo com vegetação, com declividades medidas com um clinômetro. Cada área mantinha a seguinte distância aproximada: de $100 \mathrm{~m}$ entre uma e outra. Foram utilizadas placas de alumínio com 2 a $4 \mathrm{~mm}$ de espessura com 50 $\mathrm{cm}$ de largura, sendo enterrado $10 \mathrm{~cm}$ e $40 \mathrm{~cm}$ acima do solo. Na parte inferior, foi conectada uma calha para receber o material erodido. Galões de plásticos foram interligados às calhas (ver figura ilustrativa de número 2), para captar a água com sedimentos, quando ultrapassado o limite de coleta da calha.

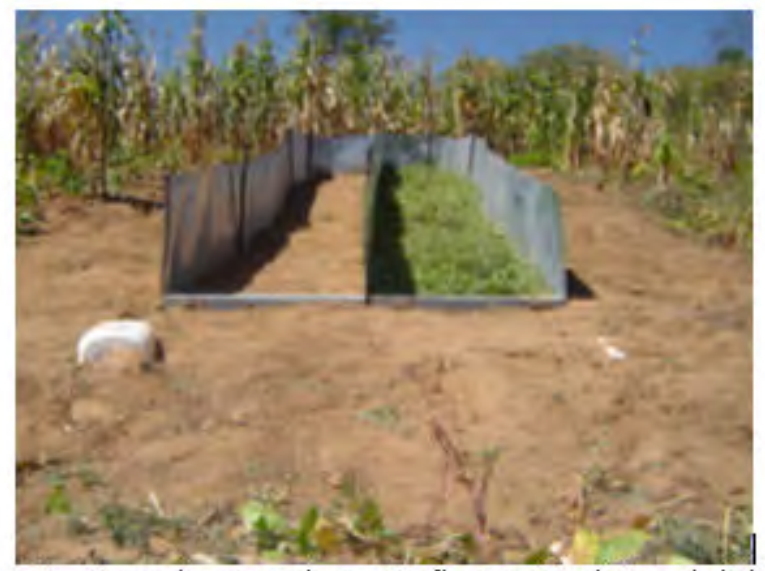

Fiaura 2: Paroela exuerimentacão em Variota. (ab/2004)
O monitoramento do processo erosivo foi realizado diariamente durante um período chuvoso, de janeiro a julho. Coletaram-se os sedimentos, em cada calha e nos galões coletores. Efetuou-se a medição, a pesagem e a análise da composição granulométrica dos sedimentos e quantidade de matéria orgânica recolhidos. A quantidade de material em cada parcela que continha vegetação não foi expressiva, e por isso as análises dos dados reportaram as demais parcelas. O índice de precipitação foi mensurado com o auxílio de um pluviômetro. Conforme Bertoni e Lombardi Neto (1999), para a determinação das perdas por erosão, sob chuva natural e com talhos munidos de sistemas coletores, os resultados tornar-seiam mais representativos ainda se a coleta fosse realizada por um tempo mais prolongado. No caso, o experimento foi realizado no período de dois anos, 2004 e 2005, somente no período chuvoso, em que os pequenos agricultores realizam a pratica da agricultura.

\section{Etapa de laboratório}

Esta etapa consistiu na análise do material coletado em campo.

O solo erodido foi pesado, e foram enviadas amostras ao Centro de Estudos Tecnológicos (CENTEC) onde foi feito análise de física, determinando os valores de areia, silte e argila, bem como a densidade e porosidade. A análise química consistiu na identificação dos nutrientes: matéria orgânica, cálcio, potássio, magnésio, pH, sódio e saturação de bases.

\section{Atividade de gabinete:}

Após tabulação dos dados do material erodido e o relacionamento do mesmo com a precipitação, foram analisados alguns fatores da Equação Universal da perda de Solos, em função dos dados disponíveis.

\section{a) A erosividade da chuva.}

Correspondeu a relação do material 
erodido com a quantidade de chuva.

\section{b) A erodibilidade.} relação:

A mesma foi analisada a partir da

$$
\frac{\% \text { areia }+\% \text { silte }}{\% \text { argila }}
$$

Com tal relação foi determinada a relação de dispersão em cada parcela do solo: $0-5 \mathrm{~cm}$; $5-10 \mathrm{~cm} ; 10-15 \mathrm{~cm} ; 15-20 \mathrm{~cm} ; 20-25 \mathrm{~cm}$ e $25-30 \mathrm{~cm}$.

\section{c) 0 fator topográfico:}

Conforme Bertoni (1959), utilizou-se a seguinte fórmula:

$$
\mathrm{LS}=0,00984 \mathrm{~L}^{0,63} \times \mathrm{S}^{1,18}
$$

Onde:

L é o comprimento da encosta, ou comprimento de rampa, em metros, porcentagem

$S$ é a declividade expressa em

\section{d)Uso, manejo e conservação do solo:}

Foi utilizada numa análise dos dados obtidos nas três diferentes parcelas de solo (co plantio, em pusio e com vegetação) em que se analisou a relação percentual de cada área.

\section{Resultados e discussões:}

Os resultados alcançados e as avaliações feitas permitiram testar alguns aspectos da Equação Universal de Perdas de Solos de Wishmeier e Smith, até hoje, o método mais conhecido e utilizado internacionalmente. Através de alguns parâmetros dessa Equação e a sua aplicação às condições da Região verfificou-se as possibilidades e limitações deste, bem como uma discussão mais séria e profunda acerca da erosão acelerada no Vale do Acaraú.

Nas áreas em que as parcelas continham vegetação não houve erosão, daí os dados serem representativos destas áreas sem vegetação. Apesar do caráter inicial em termos de pesquisa sobre erosão dos solos, em uma área de maciço no semi-árido, foi-nos permitido obter os seguintes resultados preliminares da remoção por erosão, ainda que as chuvas representaram o principal elemento climático altamente relacionado com os desequilíbrios que se apresentaram. A variação espacial da intensidade das precipitações (volume), associada a sua freqüência (concentração em alguns meses do ano), foram fatores primordiais para avaliar o resultado do material erodido. (ver quadros 1 e 2).

Verifica-se, assim, o poder da água no carreamento do solo, e este resultado é coerente com a prática realizada pelos agricultores locais que, anualmente, quando começam a preparar as terras para o plantio inicia-se o processo de remoção de nutrientes pela erosão. Nesta fase, o solo sem cobertura e, exposto à forte erosividade das chuvas no primeiro trimestre do ano, encontra-se muito vulnerável, ficando a mercê dos impactos erosivos pluviais representados pelo "splash", escoamento difuso e concentrado.

Podemos perceber nos quadros ( $1 \mathrm{e}$ 2) que a vegetação, na área de ambiente da superfície sertaneja, é um dos indicadores mais importantes das condições ambientais, uma vez que resulta da interação entre os demais componentes do meio no tempo e no espaço. Pode ser verificado que, em áreas em que a vegetação permaneceu por um maior período, o processo erosivo foi menor. 
Quadro 1: Distribuição mensal da precipitação e solo erodido em Varjota (CE). Ano 2004

\begin{tabular}{|c|c|c|c|c|c|c|c|c|c|c|c|c|c|c|}
\hline \multirow[t]{2}{*}{ Janeiro } & \multirow{2}{*}{$\mathbf{P}$} & \multicolumn{3}{|c|}{ solo erodido em área (g) } & \multirow[t]{2}{*}{ Fev. } & \multirow[b]{2}{*}{$\mathbf{P}$} & \multicolumn{3}{|c|}{ solo erodido em área (9) } & \multirow[t]{2}{*}{ Março } & \multirow{2}{*}{$\mathbf{P}$} & \multicolumn{3}{|c|}{ Solo erodido em área ( 9 ) } \\
\hline & & 1 & 2 & 3 & & & 1 & 2 & 3 & & & 1 & 2 & 3 \\
\hline 1 & & & & & 1 & 8 & 22 & 35 & 30 & 1 & 7 & 54 & 49 & 23 \\
\hline 3 & & & & & 3 & 10 & 125 & 87 & 76 & 3 & & & & \\
\hline 4 & & & & & 4 & 5 & & & & 4 & & & & \\
\hline 5 & & & & & 5 & & & & & 5 & 21 & 220 & 180 & 96 \\
\hline 6 & & & & & 6 & 10 & 98 & 102 & 32 & 6 & & & & \\
\hline 7 & & & & & 7 & 9 & 67 & 45 & 20 & 7 & 35 & 870 & 680 & 720 \\
\hline 8 & & & & & 8 & & & & & 8 & 65 & 1.780 & 1.470 & 1.640 \\
\hline 9 & & & & & 9 & 30 & & & & 9 & 63 & 1.980 & 1895 & 1.000 \\
\hline 10 & 15 & 67 & 45 & 15 & 10 & & & & & 10 & & & & \\
\hline 13 & & & & & 13 & 21 & 420 & 510 & 245 & 13 & 16 & 450 & 4800 & 390 \\
\hline 14 & & & & & 14 & & & & & 14 & & & & \\
\hline 15 & 75 & 1.850 & 1.350 & 980 & 15 & & & & & 15 & 5 & - & 10 & 5 \\
\hline 16 & & & & & 16 & 72 & 2.060 & 1560 & 1670 & 16 & & & & \\
\hline 17 & & & & & 17 & 19 & 245 & 346 & 125 & 17 & 2 & - & - & - \\
\hline 18 & 55 & 2.010 & 1.790 & 1.325 & 18 & 4 & 21 & 78 & 54 & 18 & 1 & - & - & - \\
\hline 19 & & & & & 19 & & & & & 19 & & & & \\
\hline 22 & 15 & 32 & 15 & 33 & 22 & 6 & 35 & 87 & 155 & 22 & 12 & 66 & 54 & 39 \\
\hline 23 & 25 & 350 & 450 & 120 & 23 & & & & & 23 & & & & \\
\hline 24 & & & & & 24 & 5 & 42 & 2.3 & 12 & 24 & 21 & 78 & 44 & 99 \\
\hline 25 & 147 & 6.500 & 6.400 & 5.300 & 25 & & & & & 25 & & & & \\
\hline 27 & 45 & 1.550 & 1.245 & 820 & 27 & 78 & 4.030 & 5100 & 3280 & 27 & & & & \\
\hline 28 & 15 & 45 & 110 & 135 & 28 & & & & & 28 & & & & \\
\hline 29 & 8 & 32 & 98 & 75 & 29 & 17 & 79 & 54 & 60 & 29 & & & & \\
\hline Total & 400 & 12.436 & $\begin{array}{l}11.50 \\
3\end{array}$ & 8.803 & Total & 294 & 7.264 & 8.027 & 5.759 & $\begin{array}{l}\text { To- } \\
\text { tal }\end{array}$ & 258 & 5.498 & 4.862 & 4.012 \\
\hline \multirow[b]{2}{*}{ abril } & \multirow[b]{2}{*}{$\mathbf{P}$} & \multicolumn{3}{|c|}{ solo erodido em área (9) } & \multirow[b]{2}{*}{ mais } & \multirow[b]{2}{*}{$\mathbf{P}$} & \multicolumn{3}{|c|}{ solo erodido em ărea (9) } & \multirow[b]{2}{*}{ junho } & \multirow[b]{2}{*}{$\mathbf{P}$} & \multicolumn{3}{|c|}{ Who erodido em área (9) } \\
\hline & & 1 & 2 & 3 & & & 1 & 2 & 3 & & & \begin{tabular}{l|l}
1 \\
\end{tabular} & 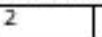 & 3 \\
\hline 3 & 6 & 73 & 67 & 44 & 3 & & & & & 3 & & & & \\
\hline 5 & & & & & 5 & 30 & 570 & 640 & 450 & 5 & & & & \\
\hline 6 & & & & & 6 & & & & & 6 & & & & \\
\hline 7 & & & & & 7 & 5 & 98 & 77 & 98 & 7 & & & & \\
\hline 8 & 5 & 22 & 48 & 32 & 8 & & & & & 8 & & & & \\
\hline 17 & 9 & 148 & 246 & 220 & 17 & & & & & 17 & 5 & 32 & 12 & 29 \\
\hline 18 & & & & & 18 & & & & & 18 & & & & \\
\hline 19 & 5 & 15 & 28 & 22 & 19 & & & & & 19 & 15 & 430 & 236 & 300 \\
\hline 20 & & & & & 20 & 14 & 358 & 125 & 210 & 20 & & & & \\
\hline 22 & & & & & 22 & & & & & 22 & 7 & 89 & 75 & 30 \\
\hline 23 & 23 & 670 & 810 & 520 & 23 & & & & & 23 & & & & \\
\hline 26 & 37 & 1.060 & 910 & 748 & 26 & & & & & 26 & & & & \\
\hline 28 & 8 & 125 & 220 & 198 & 28 & & & & & 28 & & & & \\
\hline Total & 93 & 2.133 & 2.329 & 1.784 & $\begin{array}{l}\text { Tota } \\
1^{2}\end{array}$ & 49 & 1.026 & 842 & 758 & Total & 27 & 551 & 325 & 357 \\
\hline
\end{tabular}

P - precipitação (mm)

1 - plantio 2 - pousio 3 - vegetação 
As figuras abaixo relacionam a quantidade de material erodido com volume da precipitação.

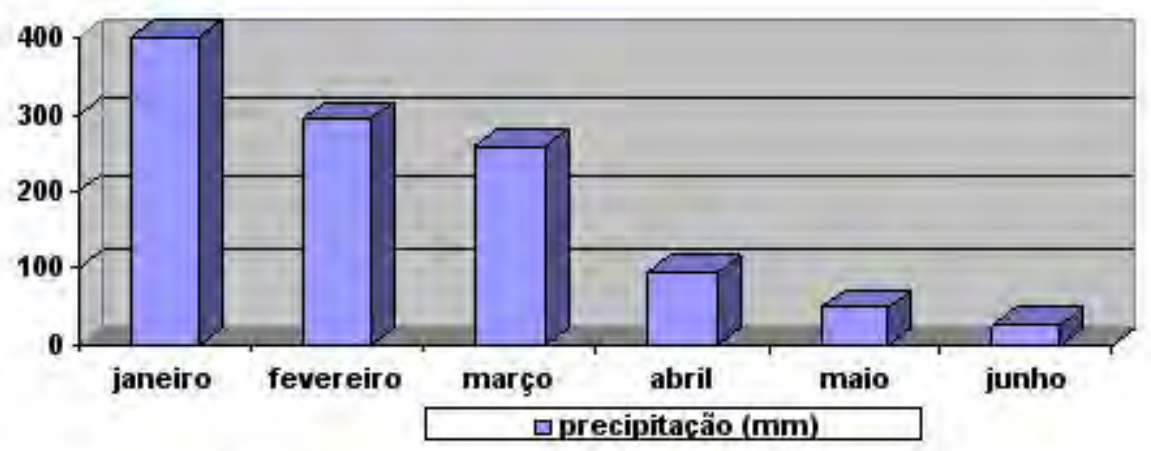

Figura 3: Índice de precipitação em Varjota. 2004.

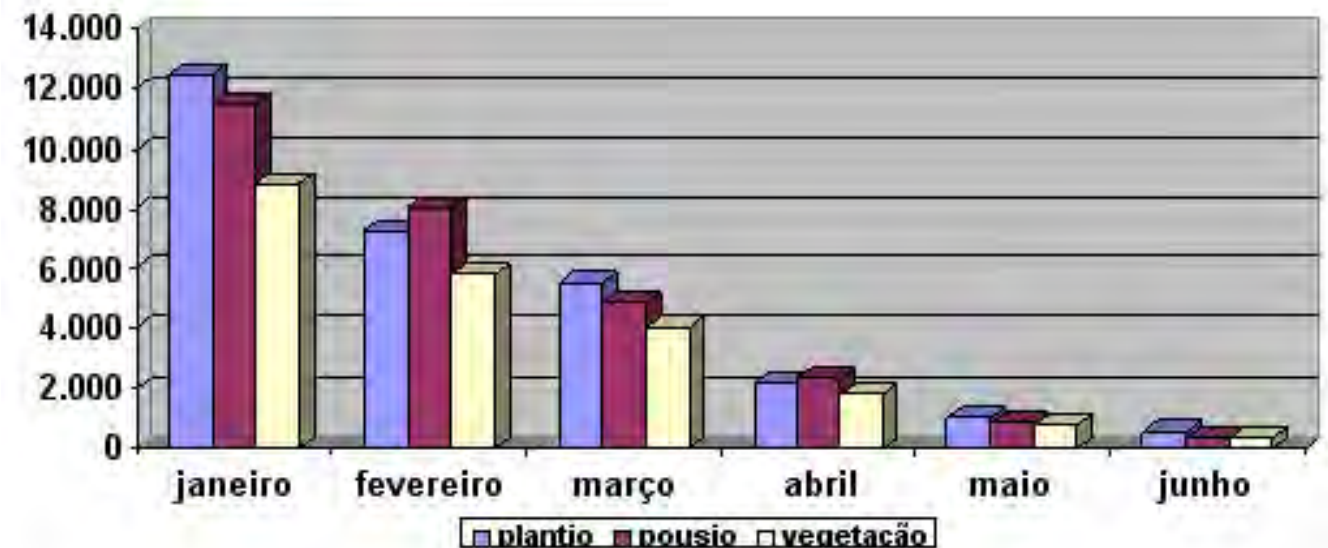

Figura 4: Solo erodido sob diferentes tipos de uso em Varjota. 2004.

Percebe-se as escalas decrescentes da precipitação, sendo acompanhadas da diminuição gradativa da erosão dos sedimentos.

A relação entre precipitação e erosão do solo, também foram proporcionais no ano de 2005, conforme mostra o quadro a seguir. 
Quadro 2: Distribuição mensal da precipitação e solo erodido em Varjota (CE) . Ano 2005

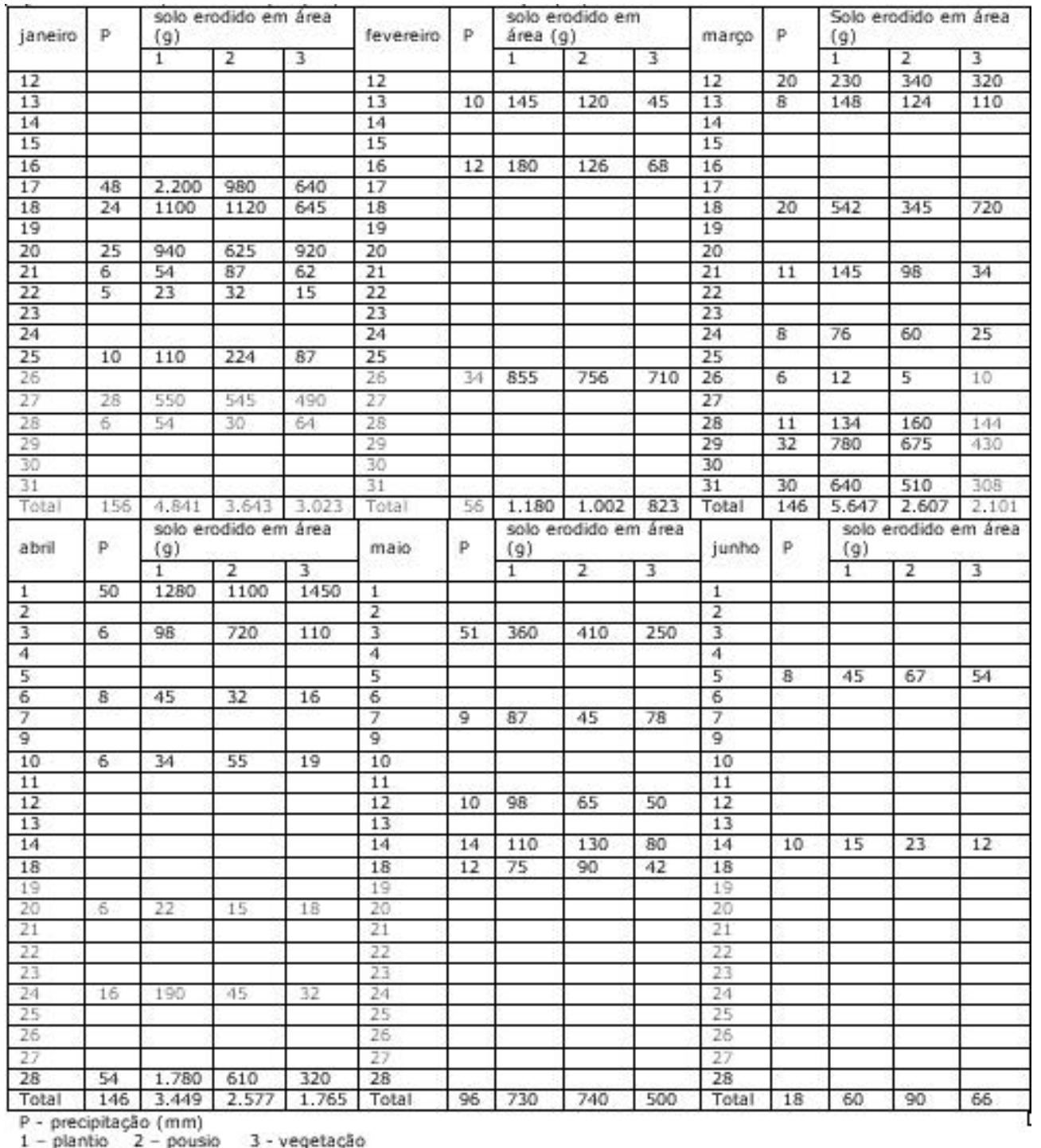

1 - plantio 2 -pousio 3 - veqetacăo 
A particularidade que se pode observar, através das figuras (5 e 6), é o índice de erosão diferenciado na parcela de plantio de milho e feijão durante os meses de março e abril.

Observa-se, ainda, que a área de plantio apresenta um menor índice de erosão entre as demais durante o mês de maio (ver figura 6), talvez em função do elevado índice de material que ela tenha erodido nos meses antecedentes e ficado acessível para deslocar-se em outros momentos de chuva.

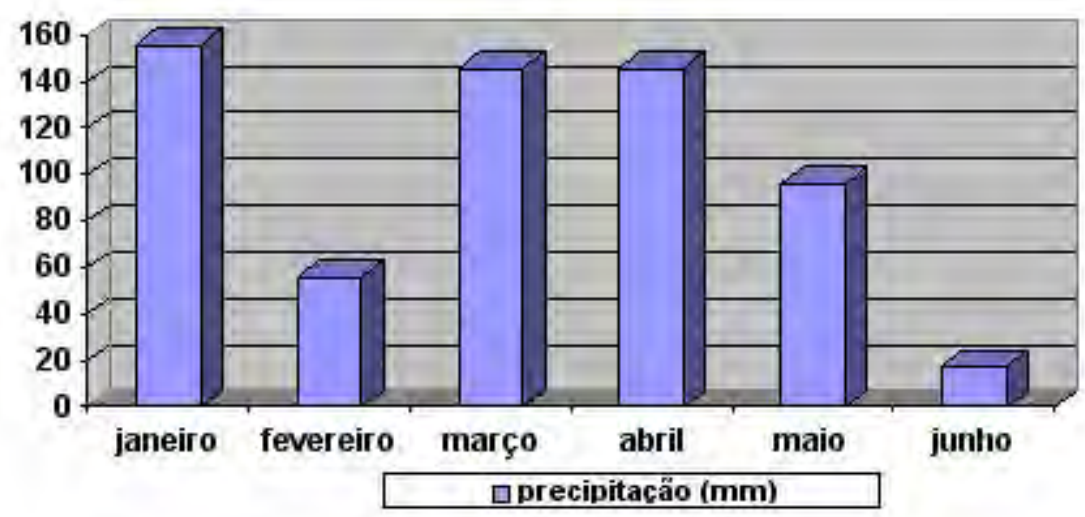

Figura 5: Índice de precipitação em Varjota. 2005.

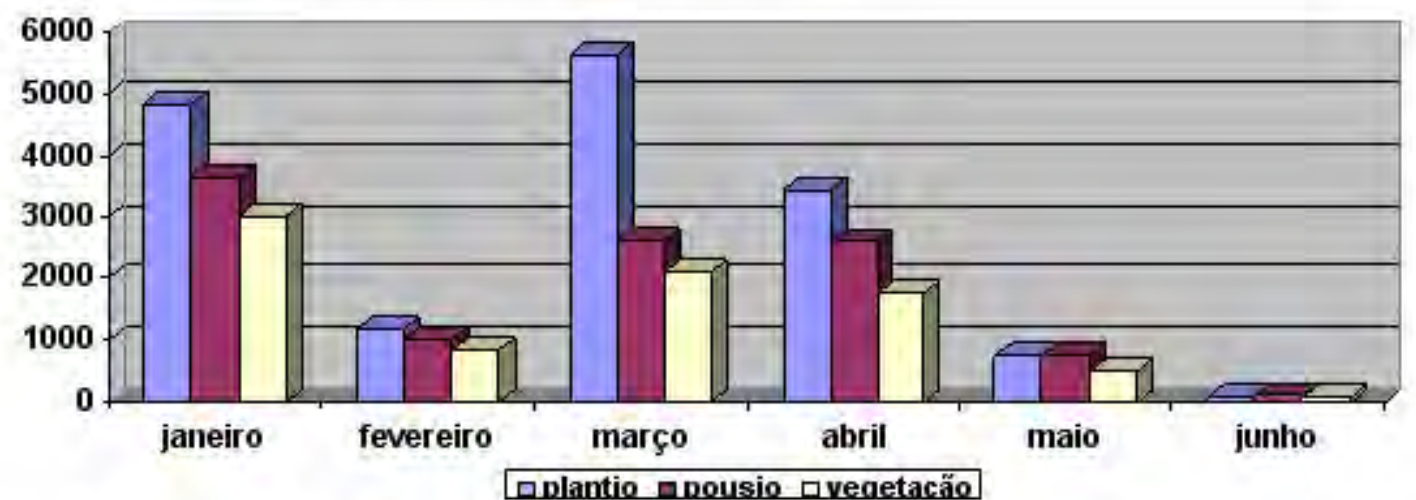

Figura 6: Solo erodido sob diferentes tipos de uso em Varjota. 2005.

De acordo com a tabela 1 , com relação às propriedades físicas, verifica-se que os solos plantados com milho e feijão apresentaram uma menor quantidade de argila na camada superficial, o que os enquadra na classe textural areia franca com menor quantidade de argila em relação aos demais sistemas de manejo que apresentaram a classe textural franco-arenosa. Em maiores profundidades, houve um predomínio da classe textural franco argilo- 
arenoso em todos os sistemas de manejo estudados.

Na área de plantio de milho e feijão a densidade do solo (Ds) atingiu um valor elevado $\left(1,49 \mathrm{~g} / \mathrm{cm}^{3}\right)$ na profundidade de $0-5 \mathrm{~cm}$, bem superior aos demais sistemas de manejo, o que caracteriza uma grave compactação e é indicativo de degradação do solo. Além disso, esse sistema de manejo mostrou uma porosidade total (PT) em torno de $43 \%$ na mesma profundidade citada em relação aos demais sistemas de manejo que apresentaram valores próximos a $50 \%$ (tabela 1 ),

É possível que o aumento de Ds e redução da PT no sistema de plantio convencional estejam relacionados com o menor teor de matéria orgânica (SILVA, 2000), o processo constante de umedecimento e secagem, além do impacto de gotas de chuvas sobre a superfície do solo em função da ausência de cobertura vegetal nessa área, favorecendo a desagregação e remoção de partículas (ALBUQUERQUE et al. 2001) e contribuindo para a translocação de partículas mais finas para os horizontes inferiores, o que leva ao entupimento dos poros. Este fato possibilita maior arraste de partículas no sentido da declividade nesse sistema, pelo efeito do escorrimento superficial de maior volume de água, o que, de certa forma, favorece os processos erosivos, implicando em danos à produtividade.

Tabela 1: Características físicas de um Argissolo sob diferentes tipos de manejo, no município de Varjota-CE.

\begin{tabular}{|c|c|c|c|c|c|c|c|}
\hline Prolundadade & $\begin{array}{l}\text { Areut } \\
\text { grossa }\end{array}$ & Area fina & Solte & Argila & $\begin{array}{l}\text { Classincaço } \\
\text { texturat }\end{array}$ & $\mathrm{D} F$ & PT \\
\hline & \multicolumn{4}{|l|}{$\rightarrow$} & & $9 \mathrm{Sin}-3$ & 果 \\
\hline \multicolumn{8}{|l|}{ S्राब aा pouse } \\
\hline$a-5 \mathrm{~cm}$ & ह1ज & 100 & $105^{-}$ & 121 & Tranco alendasa & 1,39 & 48 \\
\hline $5-10 \mathrm{tm}$ & 559 & $15 \pi$ & 150 & $124^{-}$ & Tranco arenosso & 1,33 & 51 \\
\hline $10-15 \mathrm{~cm}$ & 537 & 162 & 149 & 152 & Trancos aremaso & 1,35 & 48 \\
\hline $15-20 \mathrm{~cm}$ & 395 & 306 & 143 & 155 & franco arenoss & 1,41 & 4) \\
\hline $20-25 \mathrm{~cm}$ & 502 & 146 & 142 & 210 & $\begin{array}{l}\text { lranos argut } \\
\text { arenass }\end{array}$ & 1,40 & बहु \\
\hline $25-30 \mathrm{~cm}$ & $4 \pi 5$ & $15 B$ & 147 & 209 & $\begin{array}{l}\text { francs argiho } \\
\text { arencess }\end{array}$ & 1,44 & 45 \\
\hline \multicolumn{8}{|c|}{ Solo com matho e reja } \\
\hline $0-5 \mathrm{~cm}$ & 525 & 265 & 139 & 71 & area lianca & 1,45 & 44 \\
\hline $5-10 \mathrm{~cm}$ & $A 70$ & $2+1$ & 164 & 122 & francs arenoso & 1,33 & 48 \\
\hline $10-15 \mathrm{~cm}$ & 435 & 222 & 179 & 184 & Tranco ärencoso & 1,21 & 52 \\
\hline $15-20 \mathrm{~cm}$ & उब्ब & 2200 & 194 & 205 & $\begin{array}{l}\text { Iranco argilt: } \\
\text { aremosa }\end{array}$ & 1,22 & 51 \\
\hline $20-25 \mathrm{~cm}$ & 358 & $20 \%$ & 191 & 2क्य & $\begin{array}{l}\text { france angio } \\
\text { arenoso }\end{array}$ & 1,22 & 50 \\
\hline $25-10 \mathrm{~cm}$ & 356 & 189 & 193 & 262 & $\begin{array}{l}\text { Trances argnio } \\
\text { arenoso }\end{array}$ & 1,21 & 55 \\
\hline \multicolumn{8}{|c|}{ Sola sab vegelaça } \\
\hline $0-5 \mathrm{~cm}$ & 437 & 176 & 259 & 128 & francs arenoss & 1,29 & $A B$ \\
\hline $5-10 \mathrm{~cm}$ & -435 & 185 & 238 & 142 & Prancs aremsaso & 1,29 & 45 \\
\hline $10-15 \mathrm{~cm}$ & 304 & 162 & 258 & 196 & Jrancos arenoso & 1,25 & उह \\
\hline $15-20 \mathrm{~cm}$ & औ7 & 159 & 256 & 236 & $\begin{array}{l}\text { Jranco atgio } \\
\text { arenoso }\end{array}$ & 1,30 & 46 \\
\hline $201-25 \mathrm{~cm}$ & 320 & 149 & 243 & 285 & $\begin{array}{l}\text { franco argud } \\
\text { arencoso }\end{array}$ & 1,31 & d7 \\
\hline $25-10 \mathrm{~cm}$ & 269 & 135 & 255 & 311 & (france argulaso & 1,28 & 46 \\
\hline
\end{tabular}

Ao analisarmos a tabela 2, as taxas de erosão do material erodido em Varjota, apresentaram índices significativos nos teores de areia, silte, argila, e tudo se relaciona diretamente com o material coletado, no momento da montagem do experimento. Da mesma forma, esses dados evidenciam o empobrecimento e tendência ao declínio da capacidade de suporte e desenvolvimento vegetal indo refletir, diretamente, nas condições de equilíbrio entre adições e perdas. 
Tabela 2: Características físicas do solo erodido sob diferentes tipos de manejo, no município de Varjota -CE.

\begin{tabular}{|c|c|c|c|c|c|c|c|}
\hline Profundidade & Areia grossa & Areia fina & Silte & Argila & Classificaçá textura & DS & PT \\
\hline & \multicolumn{4}{|c|}{ (- } & & $9 \mathrm{~cm}^{-1}$ & \% \\
\hline \multicolumn{8}{|c|}{ Solo em pousio } \\
\hline 2004 & 51,3 & 13,5 & 20,1 & 15,1 & franco arenoso & 1,35 & 2,60 \\
\hline 2005 & 47,2 & 16,0 & 22,6 & 14,2 & franco arenoso & 1,31 & 2,59 \\
\hline \multicolumn{8}{|c|}{ Solb com milho e feijăo } \\
\hline 2004 & 60,2 & 13,5 & 15,8 & 10,5 & Franco arenoso & 1,39 & 2,14 \\
\hline 2005 & 59,5 & 15,0 & 14,2 & 11,3 & Franco arenoso & 1,33 & 2,25 \\
\hline \multicolumn{8}{|c|}{ Solo sob vegetaça } \\
\hline 2004 & 45,5 & 28,0 & 10,0 & 16,5 & franco arencoso & 1,29 & 2,60 \\
\hline 2005 & 44,3 & 23,0 & 15,5 & 17,2 & franco arenoso & 1,38 & 2,51 \\
\hline
\end{tabular}

Os dados revelam que, em todas as situações referentes às práticas de manejo, e o mesmo se aplica a Varjota, a precipitação não exerce uma uniformidade em termos de quantidade de chuva e de material erodido. Isso pode estar relacionado a intensidade da chuva, que, por sua vez pode relacionar-se à duas situações: (a) do fato de que a precipitação tenha se avolumado em um curto período de tempo e com isso tenha desenvolvido uma maior intensidade e (b) a distribuição resultar durante o dia, em menor velocidade e menor força.

Outra situação que difere na relação precipitação e erosão tem a ver com a deposição do solo, pois o mesmo pode percorrer no interior da calha durante certa distância e depositar-se ali, dependendo da intensidade da chuva, e, uma próxima chuva, mesmo com menor intensidade, pode ser o suficiente para o material erodido chegar à calha receptora.

Entretanto, outras situações são observadas, mediante os dados coletados:

- Erodibilidade do solo

Com base nos dados, chega-se ao fator erodibilidade do solo, que é a sua vulnerabilidade ou suscetibilidade à erosão. Um solo com alta suscetibilidade sofrerá mais erosão do que um com baixa erodibilidade, se ambos estiverem expostos a uma mesma chuva (BERTONI; LOMBARDI NETO, 1999).

Como sabemos a determinação do índice de erodibilidade é dada como sendo a razão entre a relação de dispersão (teor de argila natural/teor de argila dispersa) e a relação argila dispersa/ unidade equivalente.

Nos experimentos em Varjota, a relação de dispersão apresentou o seguinte índice:

Quadro 3: Índice de dispersão do solo em Varjota (CE)

\begin{tabular}{|c|c|}
\hline Amostra & \multicolumn{2}{|c|}{ Relaçao de dispersäo } \\
\hline $0-5 \mathrm{~cm}$ & 0,50 \\
\hline $5-10 \mathrm{~cm}$ & 0,34 \\
\hline $10-15 \mathrm{~cm}$ & 0,36 \\
\hline $15-20 \mathrm{~cm}$ & 0,51 \\
\hline $20-25 \mathrm{~cm}$ & 0,46 \\
\hline $25-30 \mathrm{~cm}$ & 0,41 \\
\hline
\end{tabular}


Nos levantamentos do PROJ ETO RADAMBRASIL (1981), para o estado do Ceará, os Podzólicos Vermelho-Amarelo, classificados, atualmente, como Argissolos, apresentaram erosão laminar ligeira, laminar moderada a laminar severa.

\section{- $\quad$ Fator topográfico}

Quanto ao fator topográfico, nos foi permitido fazer algumas considerações, pautados em Bertoni (1959), que considera o comprimento de declive da encosta e a sua declividade ( $L$ e S) normalmente analisada em conjunto (Fator Topográfico).

Em Varjota, foram obtidos os seguintes dados:

Quadro 4: Declividade da enoosta (S) e comprimento da vertente ( L ) de Varjota

\begin{tabular}{|c|c|c|c|}
\hline Identificuglio & Etasos (1) & Estacilo (2) & Estat,oo (3) \\
\hline 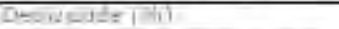 & प6. & 12,2 & 15. \\
\hline 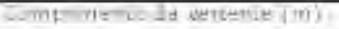 & 20,5 & 120 & $34,+1)$ \\
\hline$d x$ & Thence & 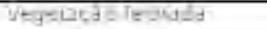 & susenc \\
\hline
\end{tabular}

Quadro 5: Valores do Fator Topográfico (L×S) de Varjota- CE

\begin{tabular}{|c|c|c|c|}
\hline (Dxs) intai & Exalde 11$\}$ & Exora $=\{2\}$ & Exorala 131 \\
\hline Fater Tatedy dian & $7.27 \pi$ & 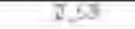 & $2,2,-1$ \\
\hline
\end{tabular}

O sistema de manejo mata fechada apresentou os maiores valores $(2,58)$ seguido do sistema pousio $(2,34)$ e plantio $(2,28)$. Essas pequenas diferenças são, exatamente, proporcionais às declividades e comprimentos das vertentes, mais suaves do que em Monsenhor Tabosa.

\section{Uso, manejo e conservação dos solos}

Nesse item, vamos avaliar o fator Uso, Manejo e Conservação dos Solos dos experimentos, sabendo de antemão que esse parâmetro da Equação Universal de Perdas de Solos, fator CP, foi o único obtido experimentalmente, contribuindo, portanto para o enriquecimento das Pesquisas em Erosão do semi-árido nordestino.

No município de Varjota a erosão do solo apresentou o seguinte resultado:

Tabela 3: Precipitação e solo erodido em diferentes sistemas de manejo no município de Varjota - CE

\begin{tabular}{|c|c|c|c|c|}
\hline \multirow[b]{2}{*}{ Meses } & \multirow[b]{2}{*}{ Precipitaçali } & \multicolumn{3}{|c|}{ Solo erodido } \\
\hline & & Plantio & Pousio & Mata \\
\hline & $(\mathrm{mm})$ & \multicolumn{3}{|c|}{ (a) } \\
\hline & \multicolumn{4}{|c|}{2004} \\
\hline Janeiro & 4015 & 12.435 & 11.5003 & 8.2003 \\
\hline Fevereiro & 294 & 7.251 & 8.027 & 6.759 \\
\hline Março & 258 & 5996 & 4.852 & 4.012 \\
\hline Abril & 93 & 2.133 & 2.329 & 1.724 \\
\hline Maio & 49 & 1.026 & ह12 & 758 \\
\hline Junho & 27 & 551 & 325 & 357 \\
\hline TOTAL & 1.129 & 28.908 & 27.928 & 22.473 \\
\hline & \multicolumn{4}{|c|}{2005} \\
\hline Janeiro & 155 & 4.801 & 3.543 & 3.023 \\
\hline Fevereiro & 56 & 1.180 & 1.002 & 823 \\
\hline Março & 146 & 5.547 & 2.6007 & 2.101 \\
\hline Abril & 145 & 3.419 & 2.577 & 1.765 \\
\hline Maio & 95 & 730 & 740 & 500 \\
\hline Junho & 18 & 60 & 90 & 65 \\
\hline TOIAL & 618 & 15.907 & 10.660 & 8.278 \\
\hline
\end{tabular}


Em 2004, com um total de $1.129,0 \mathrm{~mm}$ de chuva, o manejo relacionado ao Plantio perdeu $37 \%$ seguido do manejo Pousio, 36 \% e Mata Fechada, $27 \%$ sendo as perdas de solos proporcionais às chuvas.

Em 2005, chovendo cerca de metade do ano anterior, as perdas foram respectivamente $41 \%$ para plantio, $32 \%$ para pousio e $27 \%$ para mata fechada.

Podemos concluir que, em Varjota, as perdas de terras apresentaram resultados previstos, sendo proporcionais às chuvas e aos tipos de manejo, deduzindo-se que o manejo convencional proporcionou maior perda, seguido do pousio e, por último, da mata fechada.

Os resultados de Varjota, para o ano 2005 representaram perdas menores face às precipitações também menores, apontando o aumento do poder erosivo das chuvas quando se aumenta a sua intensidade.

A despeito da determinação experimental das perdas de solos por sistema de manejo nas condições apresentadas, uma das conclusões mais importantes do presente estudo diz respeito às altíssimas perdas de nutrientes carreados juntamente com os sedimentos. Com base em estudos efetuados em outras áreas, faremos algumas reflexões.

\section{Em área de ambiente de ambiente de superfície sertaneja (Varjota)}

Os resultados das análises químicas, organizados na tabela 4, mostram que os solos estudados apresentaram, ao longo do perfil, boas características químicas, com exceção do $P$ que mostrou baixos valores, com saturação de bases superiores a 50\%, o que Ihes confere um caráter eutróficos e pH próximo à neutralidade, conforme Alvarez V. et al. (1999). O solo sob mata mostrou ainda um maior teor de matéria orgânica na camada superficial em relação aos demais sistemas de manejo em função da queda constante de resíduos orgânicos naquele ambiente. Verifica-se uma tendência de diminuição da matéria orgânica em profundidade com exceção do sistema plantado com milho e feijão que mostrou um ligeiro aumento a partir da camada superficial até a profundidade de $20 \mathrm{~cm}$, provavelmente por perdas desta variável através de processo erosivo no horizonte superficial.

Tabela 4: Características químicas de um Argissolo, no município de Varjota -CE

\begin{tabular}{|c|c|c|c|c|c|c|c|c|c|}
\hline Profurvadade & pH & MO & $P$ & $\mathbf{K}$ & $\mathrm{Ca}$ & Mg & $\mathbf{H}+\mathbf{A l}$ & SB & v \\
\hline & $\square$ & $049 \mathrm{~kg}^{-1}$ & Mg $4 m^{2}$ & mas & 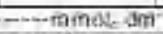 & 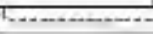 & & & $\ldots-\infty \phi_{4}-\cdots$ \\
\hline \multicolumn{10}{|c|}{ Solo em pousio } \\
\hline $0-5 \mathrm{~cm}$ & 7,1 & 13,4 & 11 & 3,4 & 29 & 14 & 5,8 & 45,4 & Bप \\
\hline $5-10 \mathrm{~cm}$ & 7,1 & 12,0 & 10 & 2,8 & 34 & 12 & $11, \sqrt{4}$ & 48,8 & 81 \\
\hline $10-15 \mathrm{Em}$ & 7,0 & 10,1 & 10 & 2,8 & 28 & 15 & 14,2 & $45, \bar{B}$ & 75 \\
\hline $15-20 \mathrm{~cm}$ & 7,1 & 10,2 & ह & 2,8 & 24 & 16 & 16,6 & $A 2, B$ & 72 \\
\hline $20-25 \mathrm{~cm}$ & 7.0 & 7,8 & 5 & 3,2 & 29 & 14 & 15,2 & 41,2 & 73 \\
\hline $25-10 \mathrm{~cm}$ & 6,9 & 5,9 & 6 & 3,2 & 24 & 14 & 14,5 & 74,0 & 74 \\
\hline \multicolumn{10}{|c|}{ Solo com milho e feifá } \\
\hline$a-5 \mathrm{~cm}$ & 7,2 & 11,4 & 4 & 3,1 & 23 & 14,0 & 26,7 & 4,1 & 60 \\
\hline $5-10 \mathrm{~cm}$ & 7,2 & 10,5 & 4 & 2,0 & 24 & 11,0 & 20,8 & 39,0 & 61 \\
\hline $10-15 \mathrm{~cm}$ & 7,1 & 11,2 & 7 & 1,5 & 30 & 10,0 & 25,4 & 41,6 & 62 \\
\hline $15-20 \mathrm{sm}$ & 2,0 & 10,9 & a & $1, \overline{6}$ & 24 & 9,0 & 25,4 & 39,3 & 61 \\
\hline $20-25=00$ & 2,7 & 9,5 & i & 1,8 & 22 & 9,2 & 22,0 & 33,0 & 60 \\
\hline $25-30 \mathrm{sm}$ & 7,1 & 9,9 & 1 & 7,6 & 27 & 9,4 & 28,4 & 41,0 & 59 \\
\hline \multicolumn{10}{|c|}{ Solo sob mata } \\
\hline$Q_{-1} 5 \mathrm{~cm}$ & 6,9 & 23,4 & 3 & 6,0 & 52 & 27 & 18,0 & 95,0 & 84 \\
\hline $5-10 \mathrm{~cm}$ & 7,0 & 19,5 & 3 & 3,4 & 48 & 22 & 10,0 & 73,4 & 68 \\
\hline $10-15 \mathrm{Em}$ & 6,9 & 14,5 & 2 & 2,8 & 48 & 24 & 13,2 & 74,6 & 85 \\
\hline $15-20 \mathrm{~cm}$ & 7,1 & 15,2 & $\sigma$ & 2,6 & 49 & 24 & 16,5 & $75,6^{-}$ & 52 \\
\hline $20-25 \mathrm{~cm}$ & 7,0 & 13,1 & 0 & 2,6 & 50 & 20 & 18,1 & 72,6 & 80 \\
\hline $25-30 \mathrm{~cm}$ & 7,0 & 9,4 & $\theta$ & 2,1 & 45 & 21 & 13,0 & 68,7 & BA \\
\hline
\end{tabular}


Com relação ao material erodido, o teor dos nutrientes foi, em geral, elevado nos três sistemas de manejo com características químicas parecidas com solos nas condições originais antes de ser erodido (Tabela 5). O magnésio revelou uma taxa de enriquecimento maior no sedimento erodido do que no solo que se originou do sistema plantado com milho e feijão Esse comportamento pode ser devido a textura do material transportado pela erosão, o qual provavelmente é rico em silte e argila, uma vez que estas frações granulométricas são as mais facilmente transportadas e mais rica em nutrientes adsorvidos (SCHINCK et al., 2000)

Tabela 5: Características químicas dos sedimentos erodidos de um Argissolo, no município de

\begin{tabular}{|c|c|c|c|c|c|c|c|c|}
\hline Maneja & pH & MO & $P$ & $\mathrm{~K}$ & $\mathrm{Ca}$ & Mg & SB & $\mathrm{v}$ \\
\hline & & $\leadsto$ dag $\mathrm{kg}^{2}-$ & 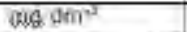 & $+\infty m+n+\infty+\infty$ & a का पन & & & $-++90+-$ \\
\hline \multicolumn{9}{|c|}{2004} \\
\hline Pousto & $\overline{6, \sqrt{6}}$ & 14,3 & 11 & 3,39 & 200,0 & 13,8 & 38.5 & 可 \\
\hline Plantio & 7,0 & 11.4 & 4 & 3,03 & 16,5 & 19,0 & 10,0 & 61 \\
\hline Mata & 7,1 & 20,4 & 6 & 4,5 & 48,1 & $22,1^{-}$ & 24,0 & 70 \\
\hline \multicolumn{9}{|c|}{52005} \\
\hline Pausio & 7,6 & 15,9 & T & 3,1 & 32,5 & 9,4 & 45 & 85 \\
\hline Plantio & 6,8 & 9,3 & 3 & 2,2 & 17,2 & 14.2 & 33.6 & 61 \\
\hline Mata & 7,2 & 19,1 & 3 & 4,8 & 51,1 & 13,5 & 59,4 & BI \\
\hline
\end{tabular}

\section{Considerações Finais}

Com relação aos fatores experimentais, embora estes tinham sido bem delimitados, o fato de a análise ter sido realizada em um aárea de dimensão limitada, leva-nos a questionar a valiodade dos dados caso fôssemos utilizá-los em $m$ modelo para fins de planejamento em todo maciço, em toda a superfície ou em toda a zona litorânea. Fica proposto que, para fins de análises, em termo de processos, é relevante considerar a importância das áreas agriculturáveis em nível de repouso, ou pousio. $E$, de fato, os dados obtidos mostraram que o fator erosão mostrou-se menos intenso nas áreas com cobertura e com maior tempo de vegetação presente, o que influiu diretamente na estrutura do solo e em seus nutrientes presentes, conforme análises físicas e químicas. Associado a isso, e condicionando o todo, o fator relevo, que, através de suas declividades, evidenciou a natureza e magnitude dos processos, acelerando o deslocar dos nutrientes em seus elementos físicos e químicos de forma que estariam condicionadas as suas declividades. Sempre maior será o processo quanto mais acentuada for a vertente.

Pode-se concluir também o índice de precipitação é um fator primordial para análise, já que os gráficos apontaram a proporção do total de chuva equivalente ao material erodido, isto nas três situações de manejo.

\section{Bilbiografia}

ALBUQUERQUE, A. W; LOMBARDI NETO, F.; SRINIVASAN, V.S. Efeito do desmatamento da caatinga sobre as perdas de solo e água de um Luvissolo em Sumé (PB). R. Bras. Ci. Solo, 25: 121-128, 2001.

ALVAREZ V. V., V.H., NOVAES, R.F.; BARROS, N.F. et al. Interpretação dos resultados das análises de solos. In RIBEIRO, A.C.; GUIMARÃES, P.T.G. \& ALVAREZ V., V.H. (Ed.) Recomendações para o uso de corretivos e fertilizantes em Minas Gerais - 5a Aproximação. Viçosa: Comissão de Fertilidade do Solo do Estado de Minas Gerais (CFSEMG), 1999, p. 25-32.

BERTONI, J; LOMBARDIO NETO. Conservação do 
solo. São Paulo. Ícone Editora. 1999.

FALCÃO, C.L.C. Avaliação dos efeitos da erosão na produtividade. XI Simpósio Brasileiro de Geografia Física Aplicada. São Paulo. Dissertação de Mestrado. UFC. Fortaleza. 2005. $98 \mathrm{p}$.

FALCÃO SOBRINHO, J. e FALCÃO, C.L.C. (Org.) Semi-Árido: diversidades, fragilidades e potencialidades. Edições Sobral. Sobral, 2006.

FALCÃO SOBRINHO, J.; FALCÃO, C.L.C. O processo erosivo e a mata ciliar do rio Acaraú na Serra das Matas (Ce). Revista Mercator/UFC, n 7.2005.

FALCÃO SOBRINHO, J. e FALCÃO, C.L.C. (2004). Técnicas de monitoramento de processos erosivos. (mimeografado). Sobral, Ceará. 10p

FUNCEME. Dados de precipitação do estado do Ceará (1984 a 2005) Fortaleza, 2006.

GOVERNO DO ESTADO DO CEARÁ. Mapa de reconhecimento de solos do estado do Ceará, escala 1:600.000, 1972.

GOVERNO DO ESTADO DO CEARÁ. Levantamento exploratório-reconhecimento de solos do estado do Ceará, escala 1:600.000. Ceará, 1978.

GUERRA, A. J. T. Geomorfologia - Exercícios, técnicas e aplicações. Capítulo 4. Rio de Janeiro, Ed. Bertrand Brasil, 139- 155, 1996.
LESPH, I.F.; BELLINAZZI J r., D; ESPINDOLA, C.R. Manual para Levantamento Utilitário do Meio Físico e Classificação de Terras no Sistema de Capacidade de Uso. SBCS. São Paulo, 1991.

ROSS, J.L.S. Geomorfologia, ambiente e planejamento. Contexto. São Paulo, 1991.

SAUER, C.O. Geografia Cultural. 1931. In. ROSENDAHL, Z; CORRÊA, R.L. Paisagem, tempo e cultura. Ed. UERJ. Rio de Janeiro. 2000. p. 1698.

SEGANFREDO, M.L.; ELTZ,, F.L.F. e BRUM, A. C. R. Perdas de solo, água e nutrientes por erosão de culturas em plantio direto. R. Bras. Ci. Solo, 21: 287-291, 1997.

SCHINCK, J ,; BERTOL, I.; BALBINOT JÚNIOR, A.A. e BATISTELA. O Erosão hídrica em cambissolo húmico alumínico submetido a diferentes sistemas de preparo e cultivo do solo: II Perdas de nutrientes e carbono orgânico. R. Bras. Ci. Solo, 24: 437-426, 2000.

SILVA, J. R. C. Erosão e produtividade do solo no semi-árido. In: OLIVEIRA, T. S. de; ASSIS J R. R. N. e ROMERO, R. E. eds. Agricultura, sustentabilidade e o semi-árido. Capítulo 10 Fortaleza; UFC, Viçosa: Sociedade Brasileira de Ciência do Solo, 169-213. 2000.

SoUZA, M. J. N. Contribuição ao Estudo das Unidades Morfo-estruturais do Estado do Ceará. In: Revista de Geologia/UFC. Fortaleza, 1988. 
